\title{
Neutralizing capacity of a new monovalent anti-Bothrops atrox antivenom: comparison with two commercial antivenoms
}

R. Otero' ${ }^{1}$, V. Núñez ${ }^{1}$,

J.M. Gutiérre $z^{4}$, A. Robles ${ }^{4}$,

R. Estrada ${ }^{4}$, R.G. Osorio ${ }^{2}$,

G. Del-Valle ${ }^{3}$, R. Valderrama ${ }^{1}$ and C.A. Giraldo ${ }^{1}$

\author{
1 Proyecto de Ofidismo, Facultad de Medicina, \\ ${ }^{2}$ Facultad de Química Farmacéutica, and \\ ${ }^{3}$ Facultad de Medicina Veterinaria y de Zootecnia, \\ Universidad de Antioquia, A.A.1226, Medellín, Colombia \\ ${ }^{4}$ Instituto Clodomiro Picado, Facultad de Microbiología, \\ Universidad de Costa Rica, San José, Costa Rica
}

\section{Correspondence \\ R. Otero \\ Proyecto de Ofidismo \\ Facultad de Medicina \\ Universidad de Antioquia \\ A.A.1226, Medellín \\ Colombia \\ Fax: 57-4-263-8282}

Research supported by the Instituto Colombiano para el Desarrollo de la Ciencia y la Tecnología Francisco José de Caldas (COLCIENCIAS), the University of Antioquia, the Direccion Seccional de Salud de Antioquia and the International Foundation for Science

(No. F/0883-4).

\section{Introduction}

Received February 23, 1996 Accepted December 2, 1996

\begin{abstract}
Three horse-derived antivenoms were tested for their ability to neu-

tralize lethal, hemorrhagic, edema-forming, defibrinating and myotoxic

activities induced by the venom of Bothrops atrox from Antioquia and

Chocó (Colombia). The following antivenoms were used: a) polyvalent (crotaline) antivenom produced by Instituto Clodomiro Picado (Costa Rica), b) monovalent antibothropic antivenom produced by Instituto Nacional de Salud-INS (Bogotá), and c) a new monovalent anti-B. atrox antivenom produced with the venom of $B$. atrox from Antioquia and Chocó. The three antivenoms neutralized all toxic activities tested albeit with different potencies. The new monovalent anti-B. atrox antivenom showed the highest neutralizing ability against edema-forming and defibrinating effects of $B$. atrox venom $(41 \pm 2$ and $100 \pm 32 \mu \mathrm{l}$ antivenom $/ \mathrm{mg}$ venom, respectively), suggesting that it should be useful in the treatment of $B$. atrox envenomation in Antioquia and Chocó.
\end{abstract}

Key words

- Bothrops atrox - Snake venom

- Antivenom

- Neutralization

- Antioquia

- Chocó
Antioquia and Chocó are located in the northwest region of Colombia, a zone with large reserves of tropical rain forest that have allowed the development of an important biodiversity, including 104 snake species (1). These regions and the Amazonas have the highest incidence of snake bites in Colombia, most of them caused by the abundant species Bothrops atrox, with a death rate of
$5 \%$ and sequelae in $6 \%$ of the patients $(2,3)$. This is mainly the result of late arrival at the hospital or, in some cases, of an insufficient antivenom supply or the high cost of lyophilized products. The venom of $B$. atrox has proteolytic, defibrinating, hemorrhagic, myotoxic, edema-forming and indirect hemolytic activities, with regional differences in venom activities (4).

These facts prompted us to produce a monovalent anti-B. atrox antivenom specific 
for the regions of Antioquia and Chocó, and to compare its neutralizing activity against homologous venom with two other crotaline antivenoms available in this region.

\section{Material and Methods}

\section{Animals, venom and antivenoms}

Webster white mice (18-20 g) were used for the in vivo experiments. The venom of $B$. atrox was a pool obtained from 40 specimens collected in Antioquia and Chocó, Colombia, lyophilized and stored at $-20^{\circ} \mathrm{C}$ until the time for use. One adult horse was immunized at Instituto Clodomiro Picado (Costa Rica) with $B$. atrox venom from Antioquia and Chocó, using the immunization protocol shown in Table 1. At the end of the immunization schedule, the horse was bled and plasma was fractionated by ammonium sulfate precipitation (5).

For comparative purposes in the neutralization experiments, the following two commercially available antivenoms were used: a) the polyvalent (crotaline) antivenom of Instituto Clodomiro Picado (ICP), San José, Costa Rica, batch 2460294 LQ, produced in horses by the same immunization schedule as described above, using a mixture of equal weights of solid venoms of $B$. asper, Lachesis muta and Crotalus durissus durissus from

Table 1 - Immunization schedule for the production of $B$. atrox monovalent and crotaline polyvalent antivenoms at Instituto Clodomiro Picado.

The venom was injected subcutaneously.

\begin{tabular}{ccl}
\hline Day No. & Venom dose $(\mathrm{mg})$ & \multicolumn{1}{c}{ Adjuvant } \\
\hline 0 & 0.75 & Freund's complete \\
10 & 1.5 & Freund's incomplete \\
20 & 3.0 & Sodium alginate \\
30 & 9.0 & Sodium alginate \\
40 & 18.0 & Sodium alginate \\
50 & 30.0 & Sodium alginate \\
60 & 45.0 & Sodium alginate
\end{tabular}

Costa Rica and, b) the monovalent antibothropic antivenom of Instituto Nacional de Salud (INS), Santafé de Bogotá, batch 140992, produced in horses immunized with B. atrox venom from various regions of Colombia. These two antivenoms were also produced using similar fractionation protocols based on ammonium sulfate precipitation of globulins, without pepsin digestion (5). Phenol $(0.25 \%)$ was added as a preservative and the antivenoms were tested before their expiration dates.

\section{Pharmacological activities of $B$. atrox venom}

The minimum edema-forming (MED), hemorrhagic (MHD) and defibrinating (MDD) doses of B. atrox venom were determined by methods described elsewhere (68), and modified by Gutiérrez et al. (9-11). Lethality (lethal dose $50 \%, \mathrm{LD}_{50}$ ) was determined by the Spearman-Karber method (12) using the ip route. Myonecrosis was evaluated by plasma creatine kinase (CK) levels and histologically by determining the myonecrosis index as described by Gutiérrez et al. $(13,14)$ and Lomonte et al. $(15)$.

\section{Neutralization assays}

The neutralization assays were perfomed by incubating a constant amount of solid venom with various dilutions of antivenom, in order to obtain several antivenom/venom ratios. Incubations were carried out at $37^{\circ} \mathrm{C}$ for $30 \mathrm{~min}$ and the mixtures were then tested in the corresponding assay systems for each pharmacological activity. The doses of venom selected to test each effect were the following: a) edema: 6 MED $=9 \mu \mathrm{g}$; b) hemorrhage: $10 \mathrm{MHD}=16 \mu \mathrm{g}$; c) defibrination: $2 \mathrm{MDD}=2.3 \mu \mathrm{g}$; d) lethality: $4 \mathrm{LD}_{50}=$ $265 \mu \mathrm{g}$; e) myonecrosis: $50 \mu \mathrm{g}$. Neutralizing ability is reported as effective dose $50 \%$ $\left(\mathrm{ED}_{50}\right)$, defined as the $\mu \mathrm{l}$ antivenom/mg venom ratio that reduces by $50 \%$ the activity of venom alone. In the case of neutralization of 
defibrinating activity, results are reported as effective dose $100 \%\left(\mathrm{ED}_{100}\right)$, defined as the $\mu \mathrm{l}$ antivenom $/ \mathrm{mg}$ venom ratio at which the effect of the venom was completely neutralized. All experiments were repeated on three different days.

\section{Statistical analysis}

Data were analyzed statistically by oneway analysis of variance (ANOVA). When the values were significantly different $(\mathrm{P}<0.05)$, the differences between pairs of means were analyzed by the Tukey test.

\section{Results}

\section{Pharmacological activities of $B$. atrox venom}

The lethal dose $50 \%$ of $B$. atrox venom injected intraperitoneally into mice was 66.2 $\mu \mathrm{g}$ (95\% confidence limits: 49.5-88.6). The minimum hemorrhagic dose was $1.6 \pm 0.6$ $\mu \mathrm{g}$, the minimum edema-forming dose $1.5 \pm$ $0.3 \mu \mathrm{g}$, and the minimum defibrinating dose $1.1 \pm 0.3 \mu \mathrm{g}$. After $\mathrm{im}$ injection of $50 \mu \mathrm{g}$ of venom, plasma CK levels increased to $664 \pm$ $116 \mathrm{U} / \mathrm{ml}$ (control mice injected with saline solution: $60 \pm 36 \mathrm{U} / \mathrm{ml}$ ) and the myonecrosis index was 1.0 (control $=0$ ), confirming the myotoxic effect of the venom.

\section{Neutralization of venom activities}

Table 2 shows that the three antivenoms neutralized all pharmacological activities of B. atrox venom studied, albeit with different potencies. Monovalent antibothropic (INS) and monovalent anti- $B$. atrox antivenoms were equally potent in the neutralization of lethality and hemorrhage, whereas the polyvalent (ICP) antivenom was less efficient in the neutralization of these effects. Regarding edema and defibrination, the monovalent anti-B. atrox antivenom showed the highest neutralizing ability. No significant differences were observed between the three antivenoms concerning neutralization of myonecrosis (Table 2).

\section{Discussion}

The parenteral administration of horseor sheep-derived antivenoms constitutes the cornerstone in the treatment of snakebite envenomation (16). Since venoms present

Table 2 - Neutralization of pharmacological activities of $B$. atrox venom from Antioquia and Chocó by the three antivenoms.

Neutralization is reported as effective dose $50 \%$ for lethal, hemorrhagic, edema-forming and myonecrotic effects and as effective dose $100 \%$ for the defibrinating effect (see Material and Methods). For lethality, results are reported as mean and $95 \%$ confidence limits (given in parentheses). For the other effects, results are reported as mean $\pm S D(N=3)$. Values with different superscripts $(a, b, c)$ are significantly different $(P<0.05)$ (Tukey test). ${ }^{+}$In the neutralization of lethality, results are also reported as $\mathrm{mg}$ venom neutralized per $\mathrm{ml}$ antivenom.

\begin{tabular}{lccccccc}
\hline Antivenom & \multicolumn{5}{c}{ Neutralization ( $\mu$ l antivenom/mg venom) } \\
\cline { 2 - 7 } & \multicolumn{2}{c}{ Lethality } & Hemorrhage & Edema & Defibrination & Myonecrosis \\
\hline Monovalent anti-B. atrox & $143(96-213)^{\mathrm{a}}$ & $71 \pm 6^{\mathrm{a}}$ & $41 \pm 2^{\mathrm{a}}$ & $100 \pm 32^{\mathrm{a}}$ & $110 \pm 20^{\mathrm{a}}$ \\
& $7.0(4.7-10.4)^{+}$ & & & & & & \\
Monovalent antibothropic (INS) & $147(100-217)^{\mathrm{a}}$ & $66 \pm 3^{\mathrm{a}}$ & $647 \pm 176^{\mathrm{c}}$ & $327 \pm 133^{\mathrm{b}}$ & $236 \pm 109^{\mathrm{a}}$ \\
& $6.8(4.6-10.0)^{+}$ & & & & & & \\
Polyvalent (ICP) & $213(149-303)^{\mathrm{b}}$ & $121 \pm 18^{\mathrm{b}}$ & $395 \pm 13^{\mathrm{b}}$ & $959 \pm 36^{\mathrm{c}}$ & $140 \pm 22^{\mathrm{a}}$ \\
& $4.7(3.3-6.7)^{+}$ & & & & & &
\end{tabular}


conspicuous biochemical and pharmacological variations between and within species (17-19), it is recommended that antivenoms should be produced in each country with venoms obtained from snakes collected in that particular region. Otero et al. (4) demonstrated variations in several pharmacological activities of B. atrox venoms obtained from different regions of Antioquia and Chocó. Thus, in order to obtain a specific antivenom against the venom of $B$. atrox from Antioquia and Chocó, a monovalent antivenom was produced and compared with two other crotaline antivenoms available in these regions.

Our results indicate that the three antivenoms were effective in neutralizing the most relevant toxic effects of $B$. atrox venom. This suggests that there is a significant immunological cross-reactivity between the venoms of $B$. atrox from Antioquia and Chocó, B. atrox from other regions of Colombia and B. asper from Costa Rica. Crossneutralization of several antivenoms produced in Latin America was demonstrated when they were tested against the venom of B. atrox from Antioquia and Chocó (20).

On the other hand, when the effective doses $50 \%$ of these antivenoms were compared, the monovalent anti- $B$. atrox antivenom produced with venoms from Antioquia and Chocó showed the highest neutralizing ability against the venom of $B$. atrox from these regions.

Local tissue damage (myonecrosis, hemorrhage and edema) is one of the most typical and dangerous consequences of $B$. atrox envenomation in Colombia (2). These effects result in severe lesions and, in a number of cases, in sequelae $(2,3)$. The rapid development of these local effects makes efficient neutralization by antivenoms difficult (9-11). Thus, it is necessary to have antivenoms with high neutralizing capacity against the toxins responsible for these effects in order to reduce the local tissue damage.

Our results indicate that the three antivenoms were similarly efficient in neutralizing myonecrosis, whereas monovalent antiB. atrox antivenom had the highest neutralizing ability against the edema-forming effect. Regarding hemorrhage, monovalent anti-B. atrox and monovalent antibothropic (INS) antivenoms were more potent than polyvalent antivenom, although all three neutralized this effect at a low antivenom/venom ratio.

In conclusion, the three antivenoms tested are efficient in neutralizing the most relevant toxic effects induced by the venom of $B$. atrox from Antioquia and Chocó. The monovalent antivenom produced with venoms from specimens collected in these regions in Colombia showed the highest neutralizing potency. We suggest that this antivenom may be of high value in the treatment of B. atrox envenomation in Antioquia and Chocó. A randomized clinical trial is currently under way in Colombia in order to test this hypothesis.

\section{Acknowledgments}

We thank Oscar Rojas (Universidad de Antioquia) and the staff of the Production Division (Instituto Clodomiro Picado) for collaboration, as well as Patricia García for typing the manuscript. 


\section{References}

1. Perez-Santos C \& Moreno AG (1988). Ofidios de Colombia. 1st edn. Museo Regionale di Scienze Naturali, Torino.

2. Otero R, Tobón GS, Gómez LF, Osorio RG, Valderrama R, Hoyos D, Urreta JE, Molina S \& Arboleda JJ (1992). Accidente ofídico en Antioquia y Chocó. Aspectos clínicos y epidemiológicos (marzo de 1989-febrero de 1990). Acta Médica Colombiana, 17: 229-249.

3. Otero R, Valderrama R, Osorio RG \& Posada LE (1992). Programa de atención primaria del accidente ofídico. Una propuesta para Colombia. latreia, 5: 96102.

4. Otero R, Osorio RG, Valderrama R \& Giraldo CA (1992). Efectos farmacológicos y enzimáticos de los venenos de serpientes de Antioquia y Chocó (Colombia). Toxicon, 30: 611-620.

5. Bolaños R \& Cerdas L (1980). Producción y control de sueros antiofídicos en Costa Rica. Boletín de la Oficina Sanitaria Panamericana, 88: 189-196.

6. Yamakawa M, Nosaki M \& Hokama Z (1976). Fractionation of sakishimahabu (Trimeresurus elegans) venom and lethal, hemorrhagic and edema-forming activities of the fractions. In: Ohsaka A, Hayashi $\mathrm{K}$ \& Sawai Y (Editors), Toxins: Animal, Plant and Microbial. Plenum Press, New York.

7. Kondo $\mathrm{H}$, Kondo $\mathrm{S}$, Ikezawa $\mathrm{H}$, Murata $\mathrm{R}$ \& Ohsaka A (1960). Studies on the quantitative method for determination of hemorrhagic activity of Habu snake venom. Japanese Journal of Medical Science and Biology, 13: 43-49.
8. Theakston RDG \& Reid HA (1983). Development of simple standard assay procedures for the characterization of snake venoms. Bulletin of the World Health Organization, 61: 949-956.

9. Gutiérrez JM, Chaves F, Bolaños R, Cerdas L, Rojas E, Arroyo O \& Portilla E (1981). Neutralización de los efectos locales del veneno de Bothrops asper por un antiveneno polivalente. Toxicon, 19: 493-500.

10. Gutiérrez JM, Rojas G, Lomonte B, Gené JA \& Cerdas L (1986). Comparative study of the edema-forming activity of Costa Rican snake venoms and its neutralization by a polyvalent antivenom. Comparative Biochemistry and Physiology, 85C: 171175.

11. Gutiérrez JM, Rojas G \& Cerdas L (1987). Ability of a polyvalent antivenom to neutralize the venom of Lachesis muta melanocephala, a new Costa Rican subspecies of the Bushmaster. Toxicon, 25: 713-720.

12. World Health Organization (1981). Progress in the Characterization of Venoms and Standardization of Antivenoms. WHO Offset Publication 58, Geneva.

13. Gutiérrez JM, Arroyo $O$ \& Bolaños $R$ (1980). Mionecrosis, hemorragia y edema inducidos por el veneno de Bothrops asper en ratón blanco. Toxicon, 18: 603610.
14. Gutiérrez JM, Rojas G, Lomonte B, Gené JA \& Chaves F (1990). La Evaluación de la Capacidad Neutralizante de los Antivenenos en América. Publicación offset, Universidad de Costa Rica, San José.

15. Lomonte $B$, Gutiérrez JM, Romero $M$ Núñez J, Tarkowski A \& Hanson LA (1993). An MTT-based method for the in vivo quantification of myotoxic activity of snake venoms and its neutralization by antibodies. Journal of Immunological Methods, 161: 231-237.

16. Warrell DA (1993). Venomous bites and stings in the tropical world. Medical Journal of Australia, 159: 773-779.

17. Jiménez-Porras JM (1964). Venom proteins of the fer-de-lance, Bothrops atrox, from Costa Rica. Toxicon, 2: 155-166.

18. Gutiérrez JM, Chaves F \& Bolaños R (1980). Estudio comparativo de venenos de ejemplares recién nacidos y adultos de Bothrops asper. Revista de Biología Tropical, 28: 341-351.

19. Chippaux JP, Williams V \& White J (1991). Snake venom variability: methods of study, results and interpretation. Toxicon 29: 1279-1303.

20. Otero R, Núñez V, Osorio RG, Gutiérrez JM, Giraldo CA \& Posada LE (1995). Ability of six Latin American antivenoms to neutralize the venom of mapaná equis (Bothrops atrox) from Antioquia and Chocó (Colombia). Toxicon, 33: 809-815. 